\title{
Factor VIII Inactivation
}

National Cancer Institute

\section{Source}

National Cancer Institute. Factor VIII Inactivation. NCI Thesaurus. Code C131666.

Presence of inactivating antibodies to factor VIII in the blood. 